\title{
Inhibition of DNA methyltransferase 1 by RNA interference reverses epithelial-mesenchymal transition in highly metastatic 95D lung cancer cells by inhibiting the Wnt signaling pathway
}

\author{
XIANCONG BU $^{1 *}$, XIANGYAN ZHANG ${ }^{2 *}$, JINHONG XU $^{3}$, HEPING YANG ${ }^{4}$, \\ XIANGDONG ZHOU ${ }^{4}$, HAIJING WANG ${ }^{4}$ and LIANG GONG ${ }^{4}$
}

\author{
${ }^{1}$ Department of Respiratory Medicine, Rizhao City Hospital of Traditional Chinese Medicine, Rizhao, \\ Shandong 276800; ${ }^{2}$ Department of Respiratory and Critical Care Medicine, Guizhou Provincial People's Hospital, \\ Guiyang, Guizhou 550002; ${ }^{3}$ Institute for Tuberculosis Control and Prevention, Guizhou Provincial Center for \\ Disease Control and Prevention, Guiyang, Guizhou 550004; ${ }^{4}$ Department of Respiratory Medicine, \\ Southwest Hospital, The Third Military Medical University, Chongqing 400038, P.R. China
}

Received September 19, 2015; Accepted March 10, 2017

DOI: $10.3892 / \mathrm{ol} .2018 .8449$

\begin{abstract}
Epigenetic modifications serve important roles in non-small cell lung cancer (NSCLC) tumorigenesis; however, the role of DNA methyltransferase 1 (DNMT1) in lung cancer progression remains unclear. In the present study, the expression of DNMT1 in the human NSCLC cell lines 95D (high invasive ability) and 95C (low invasive ability) was analyzed by western blotting. The results demonstrated that the expression of DNMT1 in 95D cells was significantly higher, compared with in 95C cells and small airway epithelial cells. To further define the role of DNMT1 in tumor migration and invasion in NSCLC cells, RNA interference was used to silence DNMT1 expression. Depletion of DNMT1 significantly inhibited 95D cell invasion and migration. In addition, treatment with DNMT1 small interfering RNA resulted in compact cell morphology and significantly increased epithelial marker E-cadherin expression whilst also decreasing the expression of certain mesenchymal markers, including vimentin and fibronectin. Suppression of DNMT1 increased cytoplasmic $\beta$-catenin levels while downregulating nuclear $\beta$-catenin and Snail, an important regulator of EMT. The results from the present study suggest that the inhibition of DNMT1 reverses the epithelial-mesenchymal transition partly via the inhibition of the Wnt/ $\beta$-catenin signaling pathway, and therefore
\end{abstract}

Correspondence to: Dr Jinhong Xu, Institute for Tuberculosis Control and Prevention, Guizhou Provincial Center for Disease Control and Prevention, 101 Ba-Ge-Yan Road, Yunyan, Guiyang, Guizhou 550004, P.R. China

E-mail: jinhong_xu6@163.com

*Contributed equally

Key words: DNA methyltransferase, epithelial-mesenchymal transition, non-small cell lung cancer, Wnt signaling pathway inhibits cell migration and invasion. These results indicate that targeting DNMT1 may inhibit tumor metastasis and that DNMT1 is a promising target for the novel treatment of lung cancer.

\section{Introduction}

Lung cancer is the principal cause of cancer-associated mortality worldwide, with an estimated 600,000 individual succumbing to the disease annually; the annual mortality rate is predicted to reach 1 million by 2025 in China (1). Non-small cell lung cancer (NSCLC) accounts for $>85 \%$ of all diagnosed cases of lung cancer and patients typically have a poor prognosis (2). At present, surgical resection remains the only curative treatment for localized tumors confined to the lung; however, $80-85 \%$ of patients present with un resectable disease at diagnosis (3). Distant metastasis leads to the majority of human cancer-associated mortalities (4). Therefore, it is important to identify sensitive and specific biomarkers for the development and progression of lung cancer.

Tumor metastasis is comprised of multiple steps. Cell invasion and migration are hallmarks of malignant transformation. Epithelial-mesenchymal transition (EMT) refers to the process whereby epithelial cells lose their epithelial phenotype and obtain a mesenchymal phenotype, which is responsible for tumor metastasis (5). During the EMT process, epithelial cells gradually lose their epithelial structures, including E-cadherin protein-mediated intercellular interactions, whilst also obtaining mesenchymal characteristics, including the upregulation of vimentin and fibronectin (6). The expression of Snail, a key transcriptional repressor of E-cadherin that can induce EMT, is controlled by a number of signaling pathways including the Wnt pathway (5).

Epigenetic changes refer to functional changes to the genomic DNA that affect gene expression but do not alter the nucleotide sequence (7). Examples of epigenetic alterations include histone modifications, DNA methylation and microRNA (miRNA/miR) expression. Epigenetic alterations 
have been proposed to be targets for cancer treatment due to their vital roles in human carcinogenesis (8). DNA methylation is a type of epigenetic modification that affects gene expression by adding a methyl group to cytosine nucleotides across the genome at cytosine-phosphate-guanine sites (9). Deregulation of DNA methylation has been reported to cause abnormal gene regulation, leading to anomalous embryonic development and diseases $(10,11)$. In addition, a number of regulators of the Wnt signaling pathway that are modulated by DNA methylation have been reported to be involved in the regulation of tumor metastasis $(11,12)$. DNA methylation is typically mediated by DNA methyltransferases (DNMTs) The DNMT family consists of four members: DNMT1, DNMT2, DNMT3A and DNMT3B (13). Among the DNMT family members, DNMT1 is primarily responsible for maintaining DNA methylation. DNMT1 mRNA expression has been reported to be elevated in NSCLC, and the elevated mRNA levels of DNMT1 occur more frequently in poorly differentiated, as compared with in well and moderately differentiated, tumor cells. In addition, elevated mRNA levels of DNMT1 were negatively associated with the overall survival time in patients with NSCLC (14).

Previous studies have demonstrated that the inhibition of DNMT1 mediates growth arrest and apoptosis in lung cancer cells (15). DNMT1 knock down induces Cyclin-dependent kinase inhibitor $1 \mathrm{~A}$ and B-cell lymphoma 2 interacting killer gene expression via an underlying mechanism independent of DNA methylation. Reduction of DNMT1 expression may prevent epigenetically mediated gene silencing and provide a novel clinical strategy to target tumor cells (16).

DNA methylation may be involved in the EMT process. For example, E-cadherin, a gene involved in cell adhesion and signaling that serves a key role in EMT, is suppressed by DNA methylation during EMT (17). The critical Smad signaling pathway that regulates EMT serves an important role in maintaining the epigenetic silencing of target genes (18). Furthermore, it has been reported that certain therapeutic agents, including mithramycin $\mathrm{A}$, are able to repress tumor metastasis via demethylation mechanisms by inhibiting the protein expression of DNMT1 (19). Although a number of studies have suggested that DNMT1 is implicated in cancer progression, its role in tumor migration, invasion and EMT remains unclear.

Thus, in the present study, the expression of DNMT1 in NSCLC cells in vitro was investigated, in addition to the effects of small interfering (si)RNA-mediated knockdown of DNMT1 expression on tumor migration and invasion, and on the EMT of NSCLC cells. In addition, the effects of DNMT1 siRNA on the matrix metalloproteinase (MMP)2 and Wnt signaling pathways were investigated in order to explore the underlying molecular mechanisms of the effect of DNMT1 on lung tumors.

\section{Materials and methods}

Cell lines. Two invasive lung cancer cell lines, 95C (low invasive ability) and 95D (high invasive ability), were purchased from The Cell Bank of Type Culture Collection of Chinese Academy of Sciences (Shanghai, China). Clonetics ${ }^{\text {TM }}$ human small airway epithelial cells (SAECs) were obtained from Lonza (Basel, Switzerland). All the cells were cultured in
RPMI-1640 medium supplemented with $10 \%$ fetal bovine serum (Invitrogen; Thermo Fisher Scientific, Inc., Waltham, $\mathrm{MA}, \mathrm{USA}$ ) in a humidified atmosphere at $37^{\circ} \mathrm{C}$ with $5 \% \mathrm{CO}_{2}$.

Plasmid construction and transfection. 95D cells were seeded in 24-well plates $\left(1.5 \times 10^{5}\right.$ cells/well) and incubated for $24 \mathrm{~h}$ in a humidified atmosphere at $37^{\circ} \mathrm{C}$ with $5 \% \mathrm{CO}_{2}$. Negative control (NC) siRNA was purchased from Ambion (Thermo Fisher Scientific, Inc.). DNMT1 siRNA was constructed as described previously (20). NC siRNA and DNMT1 siRNA were transfected into the cells using Lipofectamine ${ }^{\circledR} 2000$ (Invitrogen; Thermo Fisher Scientific, Inc.), according to the manufacturer's protocol. Following incubation for at $37^{\circ} \mathrm{C}$ for $48 \mathrm{~h}, 95 \mathrm{D}$ cells transfected with NC siRNA or DNMT1 siRNA were analyzed by reverse transcription-polymerase chain reaction (RT-PCR) and western blotting to validate the siRNA knockdown.

Immunofluorescence. 95D cells at a concentration of $1.0 \times 10^{4}$ per coverslip were seeded onto sterile coverslips and subjected to immunofluorescence analysis following NC or DNMT1 siRNA transfection. Cells were fixed with $4 \%$ paraformaldehyde at room temperature for $10 \mathrm{~min}$, permeabilized using $0.3 \%$ Triton-X-100 and then washed with PBS, followed by incubation with specific primary antibodies (anti-fibronectin; cat. no. F3648; 1:400 dilution; Sigma-Aldrich; Merck KGaA, Darmstadt, Germany; anti-E-cadherin; cat. no. 24E10; 1:600 dilution; Cell Signaling Technology, Inc., Danvers, MA, USA; anti-vimentin; 1:200 dilution; cat. no. 5741; Cell Signaling Technology, Inc.) at $4^{\circ} \mathrm{C}$ overnight Then the cells were incubated with fluorescein isothiocyanate-conjugated secondary antibodies (cat. no. ZF-0314; 1:100 dilution; Beijing Zhongshan Golden Bridge Biotechnology, Co., Ltd., Beijing, China) at $37^{\circ} \mathrm{C}$ for $1 \mathrm{~h}$. The cell nucleus was counterstained with DAPI (Invitrogen; Thermo Fisher Scientific, Inc.). Images of the stained cells were captured with a fluorescence microscope.

Western blot analysis for DNMT1 and EMT markers. RIPA lysis buffer was used for cell lysis, and a BCA Protein Assay kit (Beyotime Institute of Biotechnology, Haimen, China) was used to determine the protein concentration. Equal amounts of protein were loaded into each well for SDS-PAGE, separated by electrophoresis and transferred onto polyvinylidene fluoride membranes (EMD Millipore, Billerica, MA, USA). The membranes were blocked with $5 \%$ fat-free milk at room temperature for $1 \mathrm{~h}$. Then the membranes were probed with anti-DNMT1 (1:1,000 dilution; cat. no. sc-271729), anti-MMP2 (1:2,000 dilution; cat. no. sc-13594), anti-Snail (1:2,000 dilution; cat. no. sc-28199), anti- $\beta$-catenin $(1: 2,000$ dilution; cat. no. sc-133239), anti-GAPDH (1:1,000 dilution; cat. no. sc-47724) (all Santa Cruz Biotechnology, Inc., Dallas, TX, USA), anti-E-cadherin (1:2,000 dilution), anti-vimentin (1:1,000 dilution) and anti-fibronectin (1:1,000 dilution) overnight at $4{ }^{\circ} \mathrm{C}$, followed by incubation with horseradish peroxidase-conjugated secondary antibodies (ZB-2301; 1:3,000; ZSGB-Bio, Beijing, China) for $1 \mathrm{~h}$ at room temperature. The protein bands on the membranes were visualized using an Enhanced Chemiluminescence Detection kit (Beyotime Institute of Biotechnology). GAPDH served as the loading control. The relative amount of protein in the 
bands was quantified by densitometry using ImageJ software (version 1.46; National Institutes of Health, Bethesda, MD, USA).

$R T-P C R$. Total RNA was isolated from the 95D cells using the TRIzol ${ }^{\circledR}$ reagent (Invitrogen; Thermo Fisher Scientific, Inc.) and reverse transcribed into cDNA using a PrimeScript ${ }^{\mathrm{TM}}$ RT Reagent kit (Takara Bio, Inc., Tokyo, Japan), according to the manufacturer's protocol. The sequences of the PCR primers employed in the current study were as follows: DNMT1 forward, 5'-ACAGACAGCGTTTGGTTGAC-3' and reverse, 5'-TAGGGAACAGAAGGCAAGGG-3'; $\beta$-actin forward, 5'-CGGGAAATCGTGCGTGAC-3' and reverse, 5'-TGG AAGGTGGACAGCGAGG-3'. PCR was conducted under the following conditions: $95^{\circ} \mathrm{C}$ for $30 \mathrm{sec}, 30$ cycles of $94^{\circ} \mathrm{C}$ for $45 \mathrm{sec}, 59^{\circ} \mathrm{C}(\mathrm{DNMT}-1)$ or $54^{\circ} \mathrm{C}\left(\beta\right.$-actin) for $40 \mathrm{sec}$ and $72^{\circ} \mathrm{C}$ for $1 \mathrm{~min}$, followed by $10 \mathrm{~min}$ at $72^{\circ} \mathrm{C}$. All the PCR reactions were run in triplicate. $\beta$-actin served as an internal control. The intensity of each band amplified by RT-PCR was analyzed using Image J software.

In vitro invasion assays. For the Matrige ${ }^{\circledR}{ }^{\circledR}$ invasion assay, $8-\mu \mathrm{m}$ pore size Transwell migration chambers coated with Matrigel (BD Biosciences, San Jose, CA, USA) were used to assess the cell invasion ability. Briefly, 95D cells $\left(5 \times 10^{4}\right.$ cells/insert) transfected with NC or DNMT1 siRNA were seeded into the Matrigel-coated chambers of the 24-well plates and incubated at $37^{\circ} \mathrm{C}$ for $48 \mathrm{~h}$. After $48 \mathrm{~h}$ of incubation, non-invasive cells were removed with cotton swabs. Invaded cells were fixed in $100 \%$ methanol at room temperature for $10 \mathrm{~min}$ and then stained with $1 \%$ crystal violet at room temperature for $10 \mathrm{~min}$, rinsed with PBS and then subjected to microscopic inspection. The number of invaded cells was manually counted under an inverted microscope (magnification, x200, five random fields/well).

Wound healing assay. 95D cells ( $2 \times 10^{5}$ cells/well) were seeded into 24-well plates and grown to $\sim 95 \%$ confluence. A scratch was created in the cell monolayer using a $200 \mu \mathrm{l}$ sterile pipette tip. Serum-free RPMI-1640 medium was used to remove the floating cells and debris. Images of the wound were captured at 0 and $48 \mathrm{~h}$. The percentage of the wound healing was calculated as (the width of wound at $0 \mathrm{~h}$-the width of wound at $48 \mathrm{~h}$ )/(the width of wound at $0 \mathrm{~h}$ ), which was used to evaluate cell migration ability as previously described (21). Wounds were evaluated using Adobe Photoshop (version 7.0; Adobe Systems, Inc., San Jose, CA, USA) to measure the wound distance at 0 and $48 \mathrm{~h}$. Representative images from three independent experiments conducted in duplicate are presented in Fig. 2A.

Gelatin zymography of MMP enzyme activity. 95D cells at $2.0 \times 10^{5}$ cells per well were cultured in RPMI-1640 without serum at $37^{\circ} \mathrm{C}$ for $24 \mathrm{~h}$, and subsequently centrifuged at $1,000 \mathrm{x} \mathrm{g}$ for $10 \mathrm{~min}$ at $4^{\circ} \mathrm{C}$. The supernatants were collected and subjected to electrophoresis using 10\% SDS-PAGE with $1 \mathrm{mg} / \mathrm{ml}$ gelatin. The electrophoresis was ended when the bromophenol blue reached the bottom of the gel. The gel was transferred into a beaker and washed by gentle agitation with an eluent (2.5\% Triton-X-100) for $45 \mathrm{~min}$. After rinsing twice for $45 \mathrm{~min}$ with double distilled water, the gels were transferred into Incubation Buffer $\left(50 \mathrm{mmol} / \mathrm{l}\right.$ Tris- $\mathrm{HCl}, 5 \mathrm{mmol} / \mathrm{CaCl}_{2}$, $\left.1 \mu \mathrm{mol} / \mathrm{ZnCl}_{2}, 0.02 \% \mathrm{Brij}-35, \mathrm{pH} 76\right)$ and incubated for $42 \mathrm{~h}$ at $37^{\circ} \mathrm{C}$. The gel was then stained with $0.5 \%(\mathrm{w} / \mathrm{v})$ Coomassie brilliant blue R-250 for $2 \mathrm{~h}$ at room temperature. Finally, the gel was discolored using destaining solution A (methanol concentration, 30\%; acetic acid concentration, $10 \%$ ), destaining solution B (methanol concentration, 20\%; acetic acid concentration, $10 \%$ ) and destaining solution $\mathrm{C}$ (methanol concentration, 10\%; acetic acid concentration, 5\%) for $0.5,1$ and $2 \mathrm{~h}$, respectively. MMP activity was visualized as white bands on the blue background using Quantity One ${ }^{\circledR}$ software (version 4.6.2; Bio-Rad Laboratories, Inc., Hercules, CA, USA). The results were quantified using ImageJ software (version 1.47). Experiments were repeated $\geq 3$ times.

$\beta$-catenin reporter luciferase assay. 95D cells transfected with NC or DNMT1 siRNA were co-transfected with TOPflash or FOPflash plasmids (Upstate Biotechnology, Inc., Lake Placid, NY, USA), along with $\beta$-galactosidase expression plasmid pRL-SV40 (Promega Corporation, Madison, WI, USA), using Lipofectamine ${ }^{\circledR} 2000$ reagent. After 48 h of incubation at $37^{\circ} \mathrm{C}$, the cells were lysed and the luciferase activity was determined as described previously (22). The luciferase activity of each sample was normalized against Renilla luciferase activity to monitor transfection efficiency. $200 \mathrm{nM} \mathrm{NC}$ or DNMT1 siRNA were co-transfected with the TOPflash or FOPflash reporter. After $48 \mathrm{~h}$, luciferase activity was evaluated using the Dual-Luciferase ${ }^{\circledR}$ Reporter Assay system (Promega Corporation) normalized to Renilla luciferase activity.

Statistical analysis. Data are presented as the mean \pm standard deviation. Experiments were repeated $\geq 3$ times. Comparisons between the control and treated groups were performed using a Student's t-test. The one-way analysis of variance test was used for multiple comparisons. All the data were analyzed using SPSS software (version 13.0; SPSS, Inc., Chicago, IL, USA). $\mathrm{P}<0.05$ was considered to indicate a statistically significant difference.

\section{Results}

DNMT1 siRNA downregulates DNMT1 expression in 95D cells. To determine whether DNMT1 was associated with tumor invasion and metastasis, the protein expression levels of DNMT1 in 95C (low invasive ability) and 95D (high invasive ability) cells were compared using western blotting. The two cell lines exhibited significantly higher expression of DNMT1 compared with the SAEC cells $(\mathrm{P}<0.01$; Fig. 1A); however, the expression level of DNMT1 in 95D cells was significantly higher compared with that in 95C cells $(\mathrm{P}<0.01)$. Thus, the result indicated that DNMT1 expression level may be positively associated with the in vitro invasiveness of human NSCLC cells and the NSCLC malignancy grade. To determine whether DNMT1 may be implicated in the invasiveness of 95C and 95D cells, DNMT1 siRNA was transfected into 95D cells, which has higher DNMT1 expression levels and in vitro invasiveness. After $48 \mathrm{~h}$ of transfection, RT-PCR and western blot analysis demonstrated that DNMT1 levels in the 95D cells transfected with DNMT1 siRNA were significantly 
A

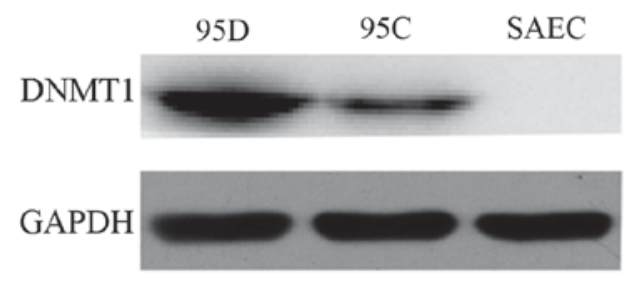

B
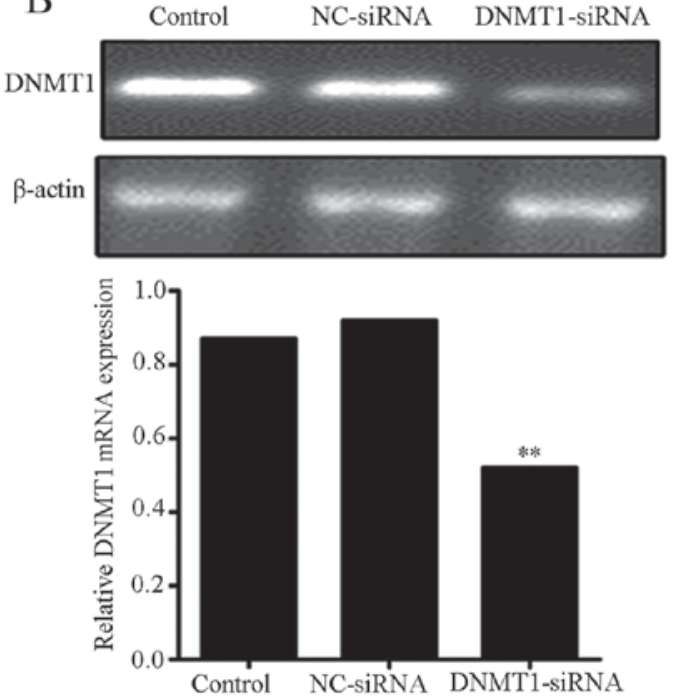

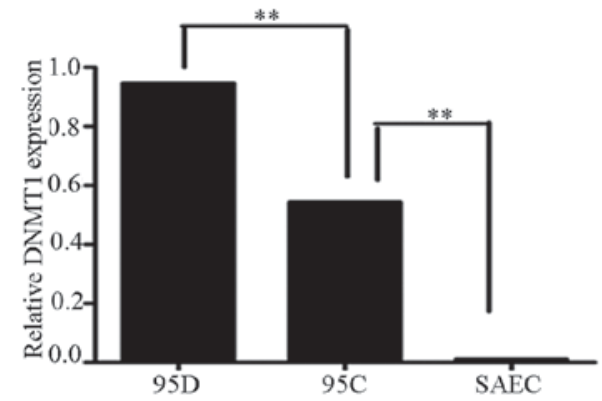

$\mathrm{C}$
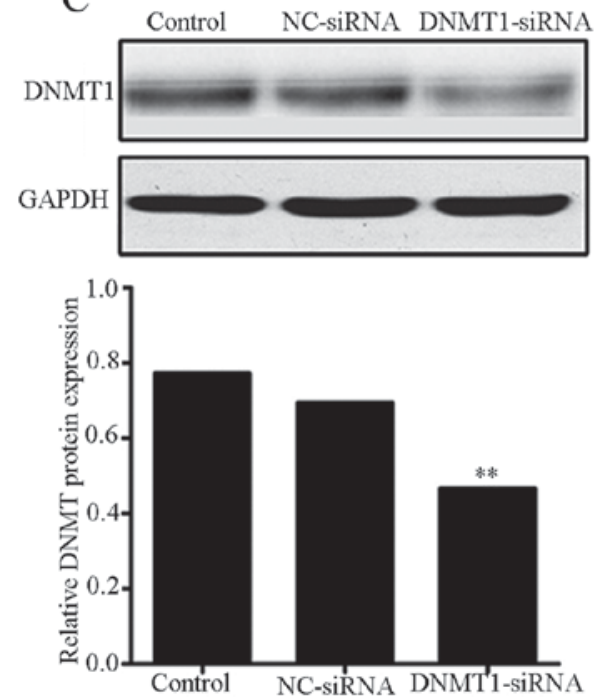

Figure 1. DNMT1 expression is significantly higher in 95D cells, compared within 95C and SAEC cells. (A) Western blot analysis of DNMT1 expression in 95D, 95C and SAEC cells. GAPDH served as the loading control. (B) RT-PCR and (C) western blot analysis of DNMT1 expression in untreated 95D cells (control) and 95D cells following transfection with DNMT1 or NC siRNA. ${ }^{* *} \mathrm{P}<0.01$, compared with the NC siRNA group. DNMT1, DNA methyltransferase 1; siRNA, small interfering RNA; NC, negative control; RT-PCR, reverse transcription-polymerase chain reaction.

lower than those in the 95D cells transfected with NC siRNA or the untreated control cells $(\mathrm{P}<0.01$; Fig. $1 \mathrm{~B}$ and $\mathrm{C})$.

Downregulation of DNMT1 by DNMT1 siRNA suppresses the migration and invasion of $95 \mathrm{D}$ cells. To determine the role of DNMT1 in the migration and invasion of 95D cells, 95D cells transfected with NC or DNMT1 siRNA were subjected to wound healing and Matrigel invasion assays. The motility and invasiveness of 95D cells transfected with DNMT1 siRNA was significantly lower compared with the control groups, which included an untreated control group and a group transfected with NC siRNA ( $\mathrm{P}<0.01$; Fig. $2 \mathrm{~A}$ and $\mathrm{B})$. To detect MMP2 enzyme activity, gelatin zymography was performed. MMP2 activity in the serum-free medium collected from 95D cells transfected with DNMT1 siRNA exhibited significantly lower enzyme activity, as compared within the NC siRNA transfected and untreated groups $(\mathrm{P}<0.01$; Fig. $2 \mathrm{C})$. These results suggest that the inhibition of DNMT1 can attenuate MMP2 activity, which then inhibits tumor invasion.

Downregulation of DNMT1 reverses EMT in 95D cells. To evaluate the role of DNMT1 on EMT, morphological alterations in cells transfected with NC or DNMT1 siRNA were examined by fluorescence microscope. The results demonstrated that the cells become more compact compared with those of the control groups (Fig. 3A). EMT-associated markers and the principal regulator transcriptional factors Snail and MMP2 were also detected by western blot analysis. The results demonstrated that E-cadherin expression was significantly increased in the DNMT1 siRNA group compared with in the NC siRNA and untreated groups $(\mathrm{P}<0.01$; Fig. 3B). However, the expression levels of vimentin, fibronectin, MMP2 and Snail were significantly lower in the DNMT1 siRNA group than in NC siRNA and control groups $(\mathrm{P}<0.01)$. To confirm these results, immunofluorescence staining was used to detect E-cadherin, vimentin and fibronectin expression. Concordant with the results of the western blot analysis, E-cadherin expression was markedly increased in the 95D cells transfected with DNMT1 siRNA, as compared with in the untreated 95D cells and 95D cells transfected with NC siRNA. These results suggest that the inhibition of DNMT1 can reverse EMT, and that DNMT1 promotes lung cancer metastasis by inducing EMT.

Inhibition of DNMT1 inhibits the Wnt signaling pathway. To elucidate the involvement of Wnt signaling in the anti-EMT effect of DNMT1 siRNA, the influence of DNMT1 siRNA on T-cell factor/lymphoid enhancer factor (TCF/LEF)-dependent transcriptional activity was examined using a dual-luciferase reporter assay. DNMT1 siRNA inhibited TCF/LEF-dependent transcriptional activity in 95D cells (Fig. 4A). Since $\beta$-catenin is an essential mediator of the Wnt/ $\beta$-catenin signaling pathway, the expression of $\beta$-catenin in 95D cells transfected with $\mathrm{NC}$ 


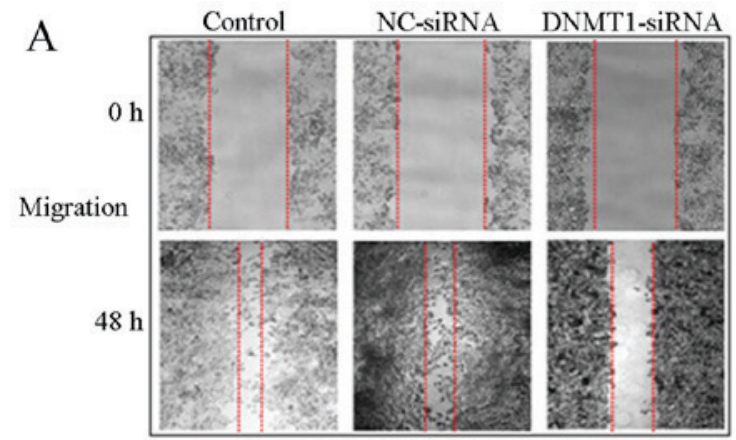

B

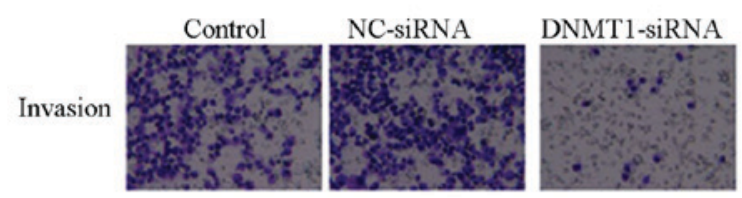

$\mathrm{C}$

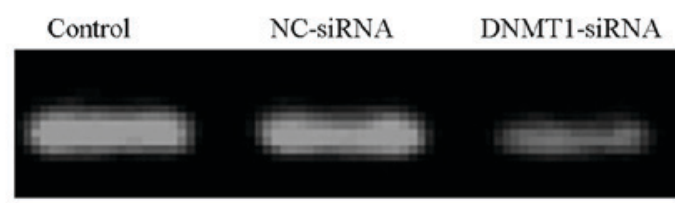

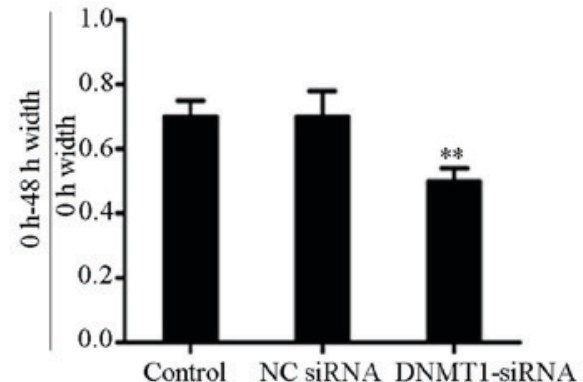
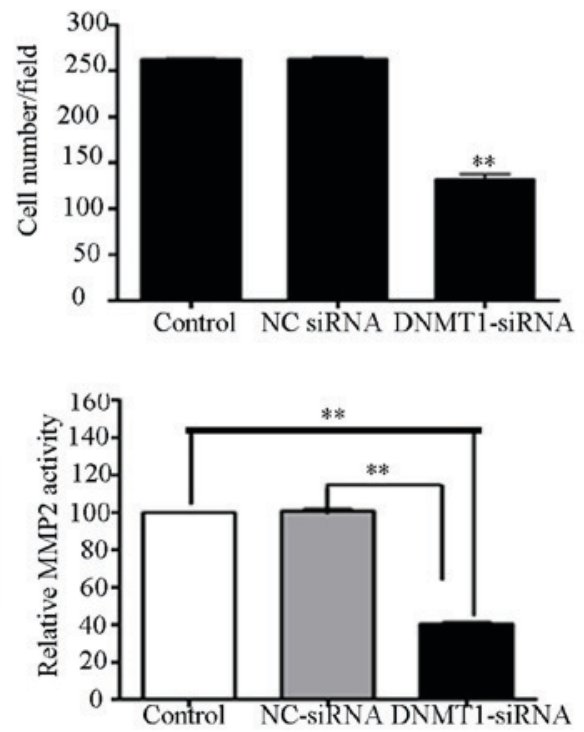

Figure 2. Depletion of DNMT1 inhibits cell migration and invasion, and MMP2 activity. (A) Wound healing assay using untreated 95D cells (control) and 95D cells transfected with NC or DNMT1 siRNA. (B) Transwell invasion assay with untreated 95D cells (control) and 95D cells transfected with NC or DNMT1 siRNA. (C) Gelatin zymography was used to examine MMP2 expression in untreated 95D cells (control) and 95D cells transfected with NC or DNMT1 siRNA. The results are representative of three independent experiments performed in duplicate. ${ }^{* *} \mathrm{P}<0.01$, compared with the NC siRNA group. DNMT1, DNA methyltransferase 1; siRNA, small interfering RNA; NC, negative control; MMP, matrix metalloproteinase.

or DNMT1 siRNA was examined. The results demonstrated that cytoplasmic $\beta$-catenin expression is significantly higher in 95D cells transfected with DNMT1 siRNA, compared within the NC siRNA and untreated groups $(\mathrm{P}<0.01$; Fig. 4B). Nuclear $\beta$-catenin expression in 95D cells transfected with NC siRNA was significantly lower compared with that in 95D cells transfected with NC siRNA or untreated groups $(\mathrm{P}<0.01)$. In addition, expression of cyclin D1 was significantly lower in the 95D cells transfected with DNMT1 siRNA group, as compared with in the control groups $(\mathrm{P}<0.01$; Fig. $4 \mathrm{C})$. These results demonstrate that the inhibition of DNMT1 can reduce tumor cell EMT through inhibiting the Wnt/ $\beta$-catenin signaling pathway.

\section{Discussion}

Lung cancer is the most common type malignancy and has a high incidence worldwide (23). The majority of patients with lung cancer present with distant metastatic lesions at the time of diagnosis; therefore, metastasis is a major cause of cancer-associated mortality. Tumor metastasis is a complex event involving extracellular matrix degradation and cell migration. Cell migration and invasion is a critical step of tumor metastasis (24). Therefore, it is necessary to identify specific molecules and protein that may inhibit cell invasion and migration.

MMPs serve critical roles in a number of cellular processes, including cell apoptosis, adhesion, migration and invasion. MMP2 is a $72-\mathrm{kDa}$ type IV collagenase that degrades the extracellular matrix, including the basement membrane (25), and is therefore associated with angiogenesis and cell migration in lung cancer progression $(26,27)$. The results of the present study demonstrated that DNMT1 siRNA significantly attenuates the motility and invasion ability of 95D cells. MMP2 activity was decreased in 95D cells transfected with DNMT1 siRNA compared with in the NC siRNA-treated or un-transfected 95D cells. This suggests that the suppression of 95D cell invasion observed following DNMT1 siRNA treatment is mediated via the inhibition of MMP2.

EMT has been reported to be an initial step in tumor metastasis (28). During EMT, polarized epithelial cells undergo a number of molecular changes, leading to the acquisition of a mesenchymal cell phenotype and subsequent increased motility and invasion. Results from the present study demonstrated that treatment with DNMT1 siRNA leads to the cells becoming more compact and to the upregulation of E-cadherin. In addition, the expression of Snail, the transcriptional suppressor of E-cadherin, and vimentin and fibronectin 
A
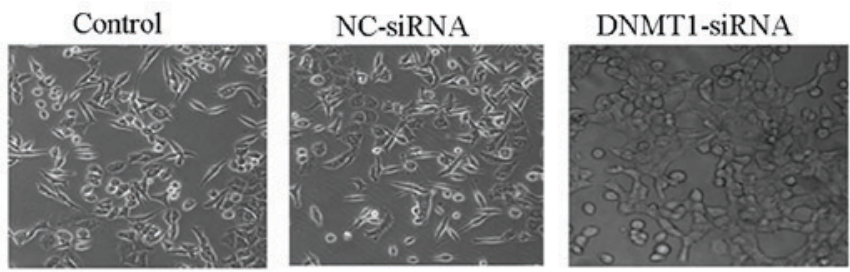

$\mathrm{B}$
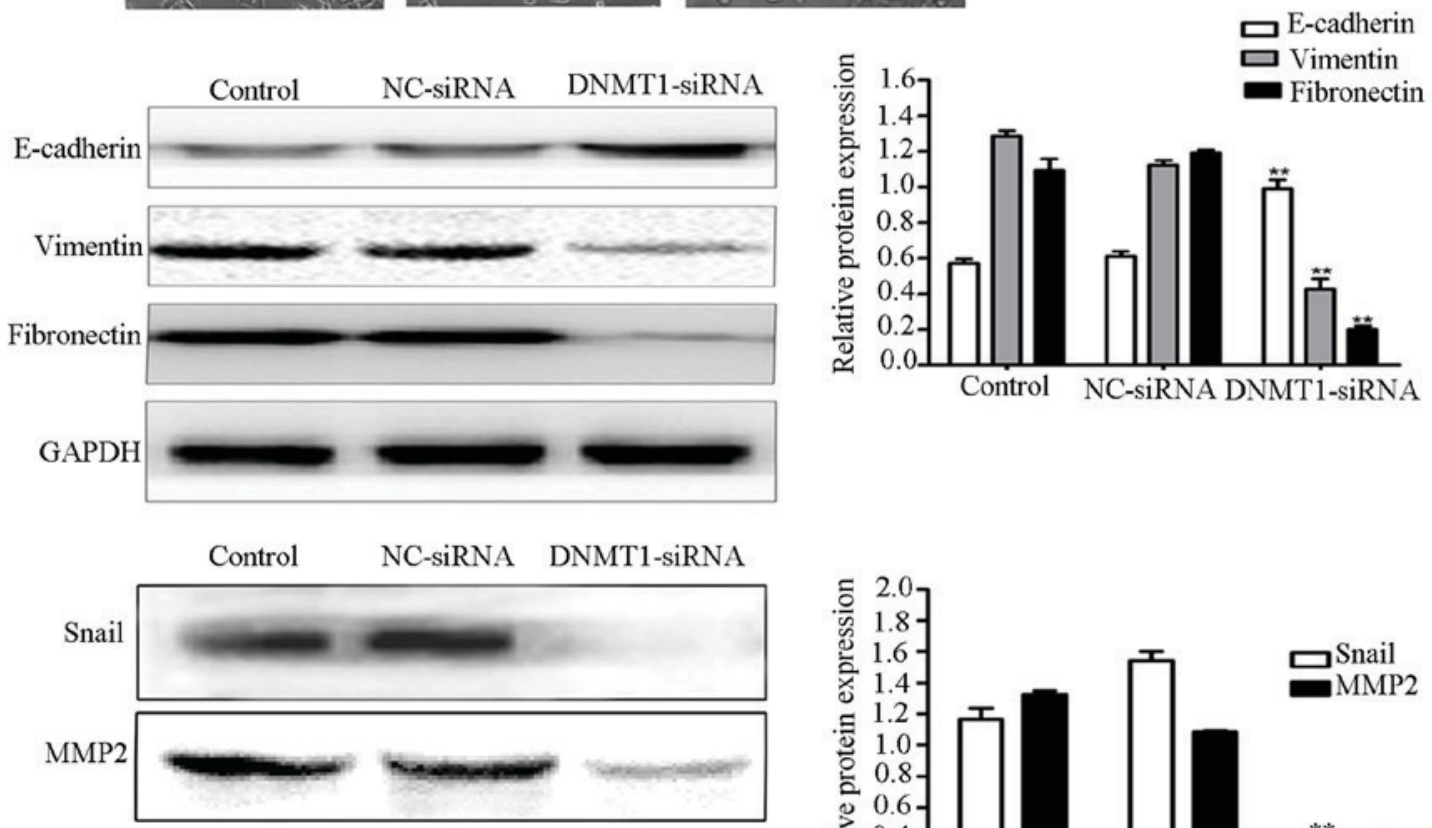

GAPDH
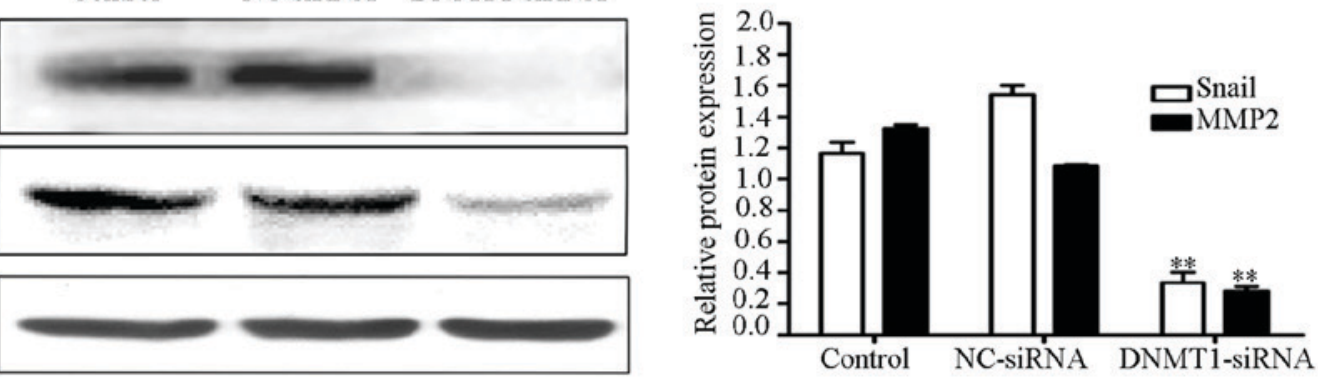

$\mathrm{C}$
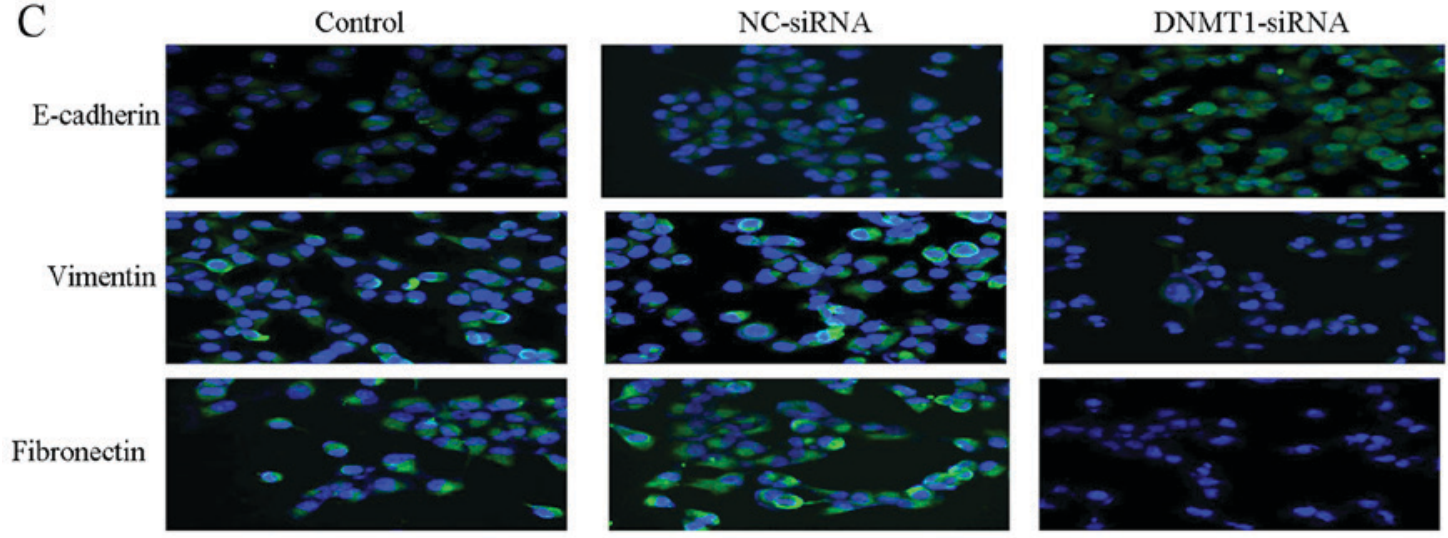

Figure 3. Downregulation of DNMT1 inhibits the epithelial-mesenchymal transition. (A) Light microscope images of untreated 95D cells (control) and 95D cells transfected with NC or DNMT1 siRNA. Magnification, x100. (B) Western blot analysis of E-cadherin, vimentin, fibronectin, Snail and MMP2 expression in untreated 95D cells (control) and 95D cells transfected with NC or DNMT1 siRNA. GAPDH served as an internal control. (C) Immunofluorescence staining of E-cadherin, vimentin, and fibronectin in untreated 95D cells (control) and 95D cells transfected with NC or DNMT1 siRNA. The green signal represents staining of the indicated proteins and the blue signal represents nuclear DNA staining by DAPI. Magnification, $x 100$. The results are representative of $\geq 3$ independent experiments. ${ }^{* *}<0.01$, compared with the NC siRNA group. DNMT1, DNA methyltransferase 1; siRNA, small interfering RNA; NC, negative control.

was downregulated by DNMT1 siRNA. These results suggest that DNMT1 siRNA can inhibit cell migration and invasion by reversing the EMT process. However, the molecular mechanisms by which DNMT1 regulates EMT remain unclear.

The Wnt signaling pathway can be divided into the canonical $\beta$-catenin-dependent pathway and the non-canonical $\beta$-catenin-independent pathway. Previous studies have demonstrated that deregulation of the Wnt signal transduction pathway contributes to EMT, cell migration, invasion and metastasis $(29,30) . \beta$-catenin, a central molecule in the Wnt signaling pathway, is a multifunctional protein involved in cell-cell adhesion, signal transduction, cellular differentiation regulation and proliferation. Previous studies have indicated that $\beta$-catenin serves a role in the onset and progression of EMT; active $\beta$-catenin is translocated to the nucleus, where it activates downstream target genes involved in $\operatorname{EMT}(31,32)$. Data from the present study demonstrated that, in addition to the attenuation of cell invasion and migration, treatment with DNMT1 siRNA 
A

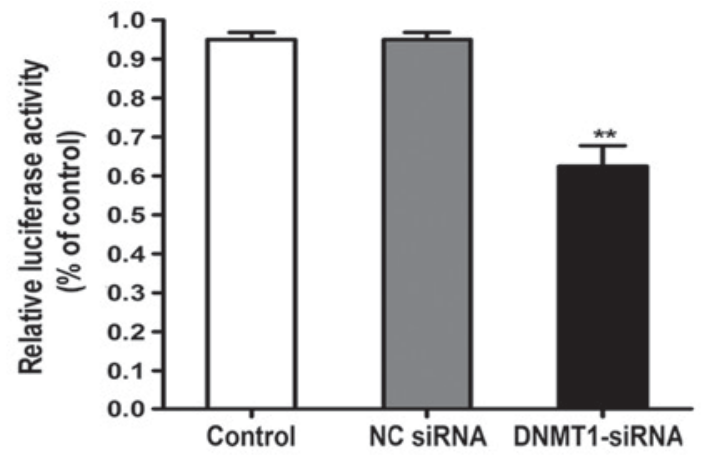

B
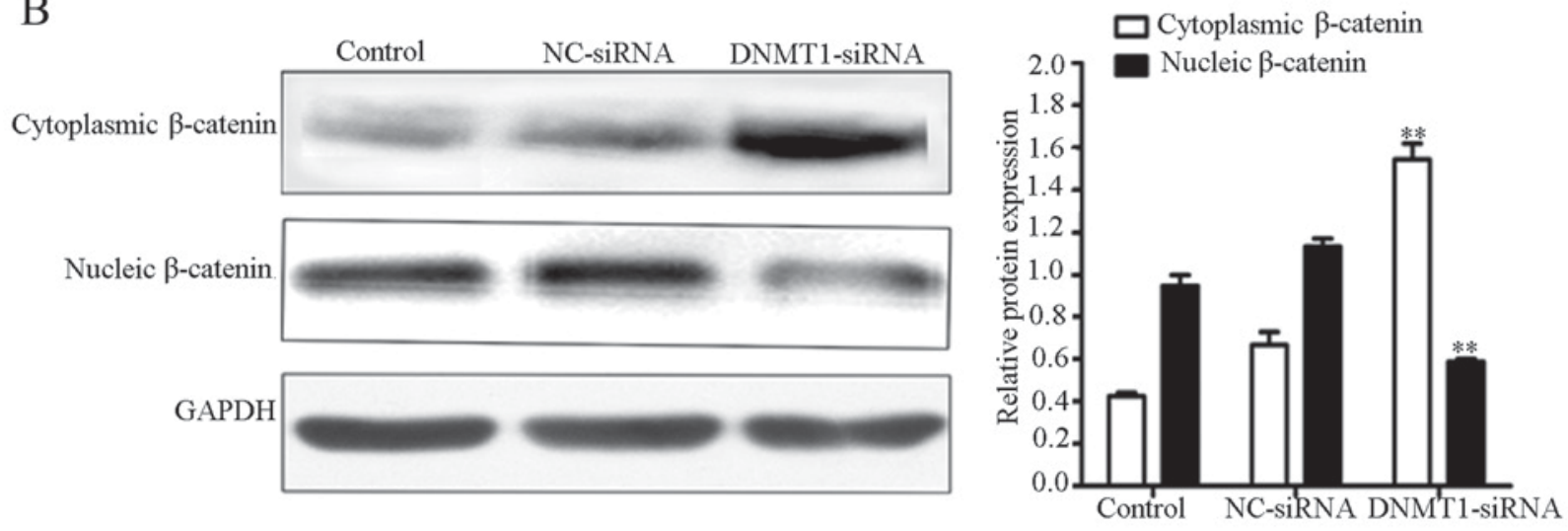

$\mathrm{C}$
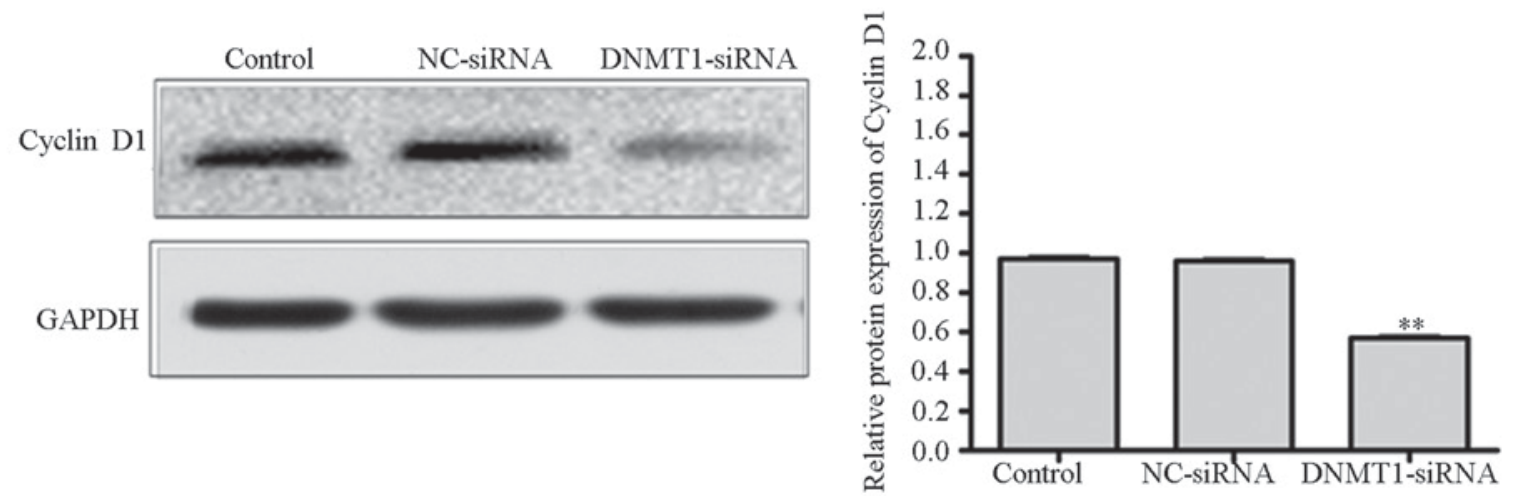

Figure 4. Downregulation of DNMT1 inhibits the Wnt signaling pathway. (A) Relative luciferase activity representing $\beta$-catenin/TCF-dependent transcription in untreated 95Dcells (control) and 95D cells transfected with NC or DNMT1 siRNA. Cells were transfected with TOPflash or FOPflash along with pRL-SV40. FOPflash served as a specificity control for TOPflash activity. The luciferase activity was normalized against Renilla activity. Experiments were repeated three times. (B) Western blot analysis of cytosolic and nuclear $\beta$-catenin expression in untreated 95D cells (control) and 95D cells transfected with NC or DNMT1 siRNA. (C) Western blot analysis of the expression of the $\beta$-catenin target cyclin D1 in untreated 95D cells (control) and 95D cells transfected with NC or DNMT1 siRNA. GAPDH served as a loading control. ${ }^{* *} \mathrm{P}<0.01$, compared with the NC siRNA group. The results are representative of $\geq 3$ independent experiments. DNMT1, DNA methyltransferase 1; siRNA, small interfering RNA; NC, negative control.

significantly decreased the levels of activated $\beta$-catenin and cyclin D1 while promoting the increase of inactivated $\beta$-catenin. As demonstrated by the dual-luciferase assay, the activity of the Wnt pathway was inhibited by DNMT1 siRNA. These results indicate that the Wnt/ $\beta$-catenin signaling pathway mediates the effects of DNMT1 siRNA on Snail-dependent EMT.

A number of molecules and proteins implicated in the Wnt signaling pathway that are mediated by DNMT1 have previously been investigated as targets for the diagnosis and treatment of malignant tumors. Downregulation of Wnt inhibitory factorl (WIF-1) has been revealed to be due to the cooperative activity of DNMT1 and DNMT3B (33). WIF-1 is a secreted antagonist of the Wnt signaling pathway. In addition, WIF-1 has been demonstrated to inhibit tumor metastasis (34). Inhibition of DNMT1 restores WIF-1 expression (20); therefore, the inhibition of DNMT1 may prevent metastasis by restoring the expression of certain anti-metastatic genes that are the target genes of the Wnt pathway. Snail and Slug have each been defined as transcriptional repressors (35).

In the present study, knockdown of DNMT1 inhibited NSCLC cell invasion and migration and downregulated $\beta$-catenin and MMP2 expression. Downregulation of nuclear $\beta$-catenin and MMP2 inhibited the Wnt signaling pathway and decreased the expression of its downstream target gene cyclin D1. In addition, Snail, an important inducer of EMT, was inhibited by DNMT1 siRNA. Therefore, the downregulation of DNMT1 leads to the downregulation of $\beta$-catenin, MMP2 and cyclin D1, and inhibits Wnt signaling pathway-dependent tumor cell migration and invasion. 
In conclusion, the results of the present study indicate a novel biological function for DNMT1 in the promotion of 95D cell invasion and migration. In addition, targeting DNMT1 may represent an effective anti-invasion and anti-migration strategy for the treatment of NSCLC, as DNMT1 may contribute directly or indirectly to tumor metastasis. However, the underlying mechanisms by which DNMT1 inhibits tumor invasion and migration remain unclear. The present study indicated that depletion of DNMT1 reverses the EMT process, as E-cadherin expression increased, whereas vimentin and fibronectin expression decreased following DNMT1 siRNA treatment. In addition, the data from the present study indicated that DNMT1 suppression inhibits tumor migration and invasion by reversing the EMT process via inhibition of the Wnt signaling pathway. Thus, a DNMT1 inhibitor may be a novel treatment used to prevent tumor metastasis; however, in vivo studies are required to validate the results of the present study.

Reduced miR-148a expression inhibits the metastasis of non-small cell lung cancer tumors by depleting DNMT1 expression (36), and miR-342 inhibits colorectal cancer cell proliferation and invasion by directly targeting DNMT1 (37). These findings support further evaluation of DNMT knockdown strategies for cancer therapy. Experiments in vitro demonstrated that DNMT1 serves a key role in the migration and invasion of lung cancer cells; however, alteration sin DNMT protein expression have not yet been demonstrated in patients with cancer, to the best of our knowledge; therefore, further studies in vivo are required to confirm the findings from the present study and to elucidate the molecular mechanisms by which DNTM1 mediates tumor metastasis.

\section{Acknowledgements}

The authors would like to thank Miss Qian Qiu, from the Department of Respiratory Medicine of Southwest Hospital (Chongqing, China) for her help.

\section{Funding}

The present study was supported by the Youth Fund of Guizhou Provincial Center for Disease Control and Prevention, China (grant no. 2014-E1-8).

\section{Availability of data and materials}

All data generated or analyzed during this study are included in this published article.

\section{Authors' contributions}

XCB, XYZ, JHX, HPY, designed the study. HJW and LG performed western blotting. XCB performed immunofluorescence, RT-PCR, wound healing and $\beta$-catenin reporter luciferase assays and analysed the data with XYZ. JHX wrote the first draft of the manuscript with XCB and $X Y Z$. HPY, XDZ, HJW, LG, XCB and XYZ contributed to the interpretation of the results and helped to write the manuscript.

\section{Ethics approval and consent to participate}

The study protocol was approved by the Ethics Committee in Rizhao City Hospital of Traditional Chinese Medicine (Shangdong, China).

\section{Consent for publication}

Not applicable.

\section{Competing interests}

The authors declare that they have no competing interests.

\section{References}

1. She J, Yang P, Hong Q and Bai C: Lung cancer in China: Challenges and interventions. Chest 143: 1117-1126, 2013.

2. Zeng L, Yu X, Yu T, Xiao J and Huang Y: Interventions for smoking cessation in people diagnosed with lung cancer. Cochrane Database Syst Rev: CD011751, 2015.

3. Jahangeer S, Forde P, Soden D and Hinchion J: Review of current thermal ablation treatment for lung cancer and the potential of electrochemotherapy as a means for treatment of lung tumours. Cancer Treat Rev 39: 862-871, 2013.

4. Cai C, Shi R, Gao Y, Zeng J, Wei M, Wang H, Zheng W and Ma W: Reduced expression of sushi domain containing 2 is associated with progression of non-small cell lung cancer. Oncol Lett 10: 3619-3624, 2015.

5. Lee SY, Jeon HM, Ju MK, Kim CH, Yoon G, Han SI, Park HG and Kang HS: Wnt/Snail signaling regulates cytochrome $\mathrm{C}$ oxidase and glucose metabolism. Cancer Res 72: 3607-3617, 2012.

6. Thiery JP and Sleeman JP: Complex networks orchestrate epithelial-mesenchymal transitions. Nat Rev Mol Cell Biol 7: 131-142, 2006.

7. Dupont C, Armant DR and Brenner CA: Epigenetics: Definition, mechanisms and clinical perspective. Semin Reprod Med 27: 351-357, 2009.

8. Allen A: Epigenetic alterations and cancer: New targets for therapy. IDrugs 10: 709-712, 2007.

9. Bacigalupo ML, Manzi M, Espelt MV, Gentilini LD Compagno D, Laderach DJ, Wolfenstein-Todel C, Rabinovich GA and Troncoso MF: Galectin-1 triggers epithelial-mesenchymal transition in human hepatocellular carcinoma cells. J Cell Physiol 230: 1298-1309, 2015.

10. Li Y, Xu Z, Li B, Zhang Z, Luo H, Wang Y, Lu Z and Wu X: Epigenetic silencing of miRNA-9 is correlated with promoter-proximal $\mathrm{CpG}$ island hypermethylation in gastric cancer in vitro and in vivo. Int J Oncol 45: 2576-2586, 2014.

11. Licchesi JD, Westra WH, Hooker CM, Machida EO, Baylin SB and Herman JG: Epigenetic alteration of Wnt pathway antagonists in progressive glandular neoplasia of the lung. Carcinogenesis 29: 895-904, 2008.

12. Ying J,Li H, Seng TJ, Langford C, Srivastava G, Tsao SW, Putti T, Murray P, Chan AT and Tao Q: Functional epigenetics identifies a protocadherin PCDH10 as a candidate tumor suppressor for nasopharyngeal, esophageal and multiple other carcinomas with frequent methylation. Oncogene 25: 1070-1080, 2006.

13. Hermann A, Gowher $\mathrm{H}$ and Jeltsch A: Biochemistry and biology of mammalian DNA methyltransferases. Cell Mol Life Sci 61: 2571-2587, 2004.

14. Kim H, Kwon YM, Kim JS, Han J, Shim YM, Park J and Kim DH: Elevated mRNA levels of DNA methyltransferase-1 as an independent prognostic factor in primary nonsmall cell lung cancer. Cancer 107: 1042-1049, 2006.

15. Kassis ES, Zhao M, Hong JA, Chen GA, Nguyen DM and Schrump DS: Depletion of DNA methyltransferase 1 and/or DNA methyltransferase $3 \mathrm{~b}$ mediates growth arrest and apoptosis in lung and esophageal cancer and malignant pleural mesothelioma cells. J Thorac Cardiovasc Surg 131: 298-306, 2006.

16. Belinsky SA, Klinge DM, Stidley CA, Issa JP, Herman JG, March TH and Baylin SB: Inhibition of DNA methylation and histone deacetylation prevents murine lung cancer. Cancer Res 63: 7089-7093, 2003. 
17. Tan EJ,Kahata K, Idas O, Thuault S,Heldin CH and Moustakas A: The high mobility group A2 protein epigenetically silences the Cdh1 gene during epithelial-to-mesenchymal transition. Nucleic Acids Res 43: 162-178, 2015.

18. Papageorgis P, Lambert AW, Ozturk S, Gao F, Pan H, Manne U, Alekseyev YO, Thiagalingam A, Abdolmaleky HM, Lenburg M and Thiagalingam S: Smad signaling is required to maintain epigenetic silencing during breast cancer progression. Cancer Res 70: 968-978, 2010.

19. Lin RK, Hsu CH and Wang YC: Mithramycin A inhibits DNA methyltransferase and metastasis potential of lung cancer cells. Anticancer Drugs 18: 1157-1164, 2007.

20. Liu Y, Wang H, Gong L, Tang C and Yang H: siRNAi targeted DNMT1 silence induces WIF-1 promoter hypomethylation. Chongqing Med J 40: 1266-1268, 2011 (In Chinese).

21. International symposium on lifestyle factors and human lung cancer. Guangzhou, China, 12-16 December 1994. Proceedings and abstracts. Lung Cancer 14 (Suppl 1): S1-S245, 1996.

22. Wang Q, Sun ZX, Allgayer H and Yang HS: Downregulation of E-cadherin is an essential event in activating beta-catenin/ Tcf-dependent transcription and expression of its target genes in Pdcd4 knockdown cells. Oncogene 29: 128-138, 2010.

23. Siegel R, Ward E, Brawley O and Jemal A: Cancer statistics, 2011: The impact of eliminating socioeconomic and racial disparities on premature cancer deaths. CA Cancer J Clin 61: 212-236, 2011.

24. Hosono Y, Yamaguchi T, Mizutani E, Yanagisawa K, Arima C, Tomida S, Shimada Y, Hiraoka M, Kato S, Yokoi K, et al: MYBPH, a transcriptional target of TTF-1, inhibits ROCK1, and reduces cell motility and metastasis. EMBO J 31: 481-493, 2012

25. Wang H, Zhu Y, Zhao M, Wu C, Zhang P, Tang L, Zhang H, Chen X, Yang Y and Liu G: miRNA-29c suppresses lung cancer cell adhesion to extracellular matrix and metastasis by targeting integrin $\beta 1$ and matrix metalloproteinase2 (MMP2). PLoS One 8: e70192, 2013.

26. Chetty C, Lakka SS, Bhoopathi P and Rao JS: MMP-2 alters VEGF expression via alphaVbeta3 integrin-mediated PI3K/AKT signaling in A549 lung cancer cells. Int J Cancer 127: 1081-1095, 2010.

27. Rojiani MV, Alidina J, Esposito N and Rojiani AM: Expression of MMP-2 correlates with increased angiogenesis in CNS metastasis of lung carcinoma. Int J Clin Exp Pathol 3: 775-781, 2010

28. Zhou J, Xie M, Shi Y, Luo B, Gong G, Li J, Wang J, Zhao W, $\mathrm{Zi} \mathrm{Y,} \mathrm{Wu} \mathrm{X}$ and Wen J: MicroRNA-153 functions as a tumor suppressor by targeting SET7 and ZEB2 in ovarian cancer cells Oncol Rep 34: 111-120, 2015.
29. Fu Y, Zheng S, An N, Athanasopoulos T, Popplewell L, Liang A, $\mathrm{Li} \mathrm{K}, \mathrm{Hu} \mathrm{C}$ and Zhu Y: $\beta$-catenin as a potential key target for tumor suppression. Int J Cancer 129: 1541-1551, 2011.

30. Valenta T, Hausmann G and Basler K: The many faces and functions of $\beta$-catenin. EMBO J 31: 2714-2736, 2012

31. Oh SJ, Shin JH, Kim TH, Lee HS, Yoo JY, Ahn JY, Broaddus RR, Taketo MM, Lydon JP, Leach RE, et al: $\beta$-Catenin activation contributes to the pathogenesis of adenomyosis through epithelial-mesenchymal transition. J Pathol 231: 210-222, 2013.

32. Zhao JH, Luo Y, Jiang YG, He DL and Wu CT: Knockdown of $\beta$-catenin through shRNA cause a reversal of EMT and metastatic phenotypes induced by HIF-1 $\alpha$. Cancer Invest 29: 377-382, 2011.

33. Quan H, Zhou F, Nie D, Chen Q, Cai X, Shan X, Zhou Z, Chen K, Huang A, Li S and Tang N: Hepatitis $C$ virus core protein epigenetically silences SFRP1 and enhances HCC aggressiveness by inducing epithelial-mesenchymal transition. Oncogene 33: 2826-2835, 2014

34. Yee DS, Tang Y, Li X, Liu Z, Guo Y, Ghaffar S, McQueen P, Atreya D, Xie J, Simoneau AR, et al: The Wnt inhibitory factor 1 restoration in prostate cancer cells was associated with reduced tumor growth, decreased capacity of cell migration and invasion and a reversal of epithelial to mesenchymal transition. Mol Cancer 9: 162, 2010.

35. Haslehurst AM, Koti M, Dharsee M, Nuin P, Evans K, Geraci J, Childs T, Chen J, Li J, Weberpals J, et al: EMT transcription factors snail and slug directly contribute to cisplatin resistance in ovarian cancer. BMC Cancer 12: 91, 2012.

36. Chen Y, Min L, Zhang X, Hu S, Wang B, Liu W, Wang R, Gu X, Shen W, Lv H, et al: Decreased miRNA-148a is associated with lymph node metastasis and poor clinical outcomes and functions as a suppressor of tumor metastasis in non-small cell lung cancer. Oncol Rep 30: 1832-1840, 2013.

37. Wang H, Wu J, Meng X, Ying X, Zuo Y, Liu R, Pan Z, Kang T and Huang W: MicroRNA-342 inhibits colorectal cancer cell proliferation and invasion by directly targeting DNA methyltransferase 1 . Carcinogenesis 32: 1033-1042, 2011. International (CC BY-NC-ND 4.0) License. 